\title{
DANÇA EM ESPAÇOS URBANOS: REFLEXÕES E REPRESENTAÇÕES DE BAILARINOS E COREÓGRAFOS
}

\section{Dance in urban spaces: \\ Reflections and representations of dancers and choreographers}

\author{
Bianca Christian Medeiros Sales \\ Andréa Bergallo Snizek \\ Universidade Federal de Viçosa - UFV
}

Resumo: O presente artigo busca refletir a relação entre corpo, criação e espaços de veiculação de obras de dança. Objetivou-se analisar o modo de composição/ manutenção de duas obras artísticas do PROJETO NEPARC - Núcleo de Estudos e Práticas Artístico-Corporais. Trata-se de um estudo com abordagem qualitativa, que teve como amostra dançarinos e coreógrafos que compuseram o PROJETO no ano de 2013.

Palavras-chave: Dança Contemporânea; Intervenções artísticas; Espaço Urbano.

Abstract: The present article aims to discuss the process of choreographic works made to be shown in urban spaces, the objective was to analyze the composition/ maintenance of two artistic works by NEPARC PROJETO - Núcleo de Estudos e Práticas Artístico-Corporais. It consists of a qualitative approach study, the sample was made with dancers and choreographers who composed the Project in 2013.

Keywords: Contemporary Dance; Artistic interventions; Urban space. 
Ao integrar o PROJETO NEPARC - Núcleo de Estudos e Práticas Artístico-Corporais, observou-se que havia discrepância no que dizia respeito ao local onde ocorriam as criações/manutenções dos trabalhos coreográficos, em contraposição ao local em que o Projeto e as obras que o compunham comprometiam-se a atuar.

O processo de composição-manutenção dos espetáculos sucedia em estúdios de dança especializados; todavia, a apresentação tinha como destino o espaço urbano (rua), local que possui uma organização e contexto específico.

No ano de 2013, o NEPARC finalizou seu primeiro espetáculo, "Por enquanto é isso...", composto por três obras artísticas, entre elas, a remontagem de "Outro Lugar", de Alex Neoral (RJ), e a composição de "Plástico Bolha", de Vanilto Alves de Freitas, o Lakka (MG), obras selecionadas para a análise dessa pesquisa.

Entendendo a rua como um organismo vivo e dinâmico, buscou-se refletir acerca da relação entre o bailarino-espetáculoespaços de veiculação (espaço urbano e espaço especializado). Percebeu-se a importância de estudar os processos de criação das obras artísticas destinadas à cidade do referido Projeto, partindo do pressuposto que os locais onde ocorrem as composições/ manutenções técnicas corporais (estúdios de dança), em relação aos espaços de apresentações (espaços públicos), possuem características distintas. Desta forma, trabalhou-se com a hipótese de que essas divergências poderiam afetar a obra, a performance dos bailarinos e, na mesma proporção, a integridade física dos artistas.

Foram consideradas como referências as seguintes informações: 1) as percepções dos coreógrafos acerca do processo de criação dos espetáculos; 2) as representações dos intérpretescriadores sobre questões pertinentes aos processos experimentados, estratégias de preparação física (manutenção e aperfeiçoamento técnico corporal), e espaços sugeridos para exposição dos trabalhos.

Trata-se de um estudo qualitativo, no qual foram utilizadas as seguintes técnicas: entrevista do tipo semiestruturada e observação participante. As discussões feitas se estruturam em dois eixos norteadores: Dança Contemporânea e Espaço Urbano, de modo que alguns dos autores utilizados foram: Fazenda (2007), Cohen (1989), Lepecki (2011), Traquino (2010) e Britto e Jacques (2008a; 2008b; 2009).

O objetivo do estudo é buscar, nas percepções de coreógrafos e bailarinos, informações que permitam a análise reflexiva entre o processo de construção artística $^{1}$ e o contexto/ cultura onde esse se dá, contexto de criação/ processo e de exposição.

1 Preparação artística neste texto compreende procedimentos como laboratórios de criação e pesquisa de movimento, preparação corporal e discussões relativas à dramaturgia de cada obra. 


\section{Corpo-Cidade: Cartografia X Corpografia ${ }^{2}$}

O território urbano no mundo contemporâneo se caracteriza por alto grau de delimitação e monitoramento, que poderíamos caracterizar como um espaço gráfico constituído de elementos que o organizam/ delimitam, afetando-o e paralelamente atendendo o seu funcionamento, como por exemplo: faixas de pedestres, placas de trânsito, itinerários de ônibus, trilhos guia para pessoas com deficiência e etc.

Estes elementos engendram uma cartografia urbana composta de "códigos sociais" que atuam no controle dos corpos no espaço, afetando e direcionando suas percepções espaço-temporais e, portanto, direta e indiretamente, seus processos de subjetivação.

Segundo Certeau (1994), uma relação direta com o espaço é um fator imprescindível para se obter uma experiência sensorial, o que o autor intitula "cruzamento de móveis". A figura do andarilho é seu maior exemplo, pois o indivíduo interage diretamente com o ambiente urbano, diferentemente de uma pessoa em um automóvel, que se relaciona com o espaço de forma passiva, realidade que, para o autor, levará o indivíduo do carro a uma desconexão com o meio.

2 Este termo é utilizado por Britto e Jacques (2009). Em seus estudos sobre Corpo-Cidade, as autoras afirmam que corpografia é uma espécie de grafia urbana, é a cidade vivida que fica inscrita, mas que também compõe o corpo de quem a experimenta.
Sennet (2001) ressalta que a arquitetura e o urbanismo distanciaram-se do corpo, o que, para o autor, contribui para certa carência de experiências sensoriais de seus habitantes. O movimento Situacionista, conforme Debord (1997) critica a prática monopolista dos arquitetos e urbanistas que planejam a cidade sem a participação da população.

O aspecto crucial dessa configuração contemporânea das cidades, que interessa salientar, é o do empobrecimento da experiência urbana dos seus habitantes, cujo espaço de participação civil, de produção criativa e vivência afetiva não apenas está cada vez mais restrito quanto às suas oportunidades de ocorrência, mas inclusive, qualitativamente comprometido quanto às suas possibilidades de complexificação. (BRITTO e JACQUES, 2009, p. 338-339)

"Existe uma relação íntima e biunívoca entre a vivência corporal e o planejamento urbano, a cidade molda o aparato social inferindo diretamente em nossa forma de percepção do meio, e como consequência, a forma de interação entre os indivíduos" (FREITAS, 2011, p. 21).

Pensar que a organização urbana atua no controle do espaço, fazendo refém a percepção do sujeito, sendo que nesse sistema o objetivo não é impedir, mas controlar os movimentos dos corpos, nos faz repensar os usos do espaço e da lógica de cada cultura.

Essa ação de "ordenação" é realizada pelas tecnologias de vigilância e pelas 
ações policiais, o termo "coreopolícia", utilizado por Lepecki (2011), diz ser a polícia o órgão responsável por manter a organização da cidade e de seus códigos que foram previamente elaborados e instituídos.

Os códigos estabelecidos pela urbanidade podem e são reinventados, portanto, ressignificados e reinterpretados, e quando tais mudanças se dão, ainda que provisórias, emergem vulnerabilidades no decoro urbano. Esta desorganização do cotidiano é uma ação praticada na relação corpo-cidade que propõe mudanças nos ambientes outrora projetados.

Britto e Jacques (2009) consideram que a analogia entre corpo e espaço é reflexo do posicionamento socioeconômico, político e cultural do homem na sociedade, já que o ser humano constrói a cidade e é construído por ela.

A relação Corpo-Cidade ${ }^{3}$ reorganiza e problematiza a organização social espacial, do cotidiano, e, em especial, as interferências artísticas dinamizam tal relação, a cada ruptura gera-se uma nova proposta de transformação da estrutura planejada. Nesse sentido, o artista acaba por intervir na cartografia, provocando novas dinâmicas, agindo como coautor. $O$ artista constrói uma relação corporal com a cidade, diferentemente de um transeunte, propondo-se estar nela, vivenciá-la como uma estrutura constituinte da obra.

Nesse sentido, as intervenções artísticas urbanas podem ser entendidas como 3 Compreendida aqui, conforme Freitas (2011), como uma relação entre a vivência corporal e o planejamento urbano. ações políticas, em parte por questionarem ou destacarem as delimitações espaciais impostas ao cidadão. Para Agamben (2008 apud LEPECKI, 2011, p. 44), “a arte é inerentemente política, porque é uma atividade que torna inativos, e comtempla, os hábitos sensoriais e os hábitos gestuais dos seres humanos, $\mathrm{e}$, ao fazê-lo, os abre para um novo uso potencial". Em suma, a dança possui capacidade de teorizar o contexto social, opera como uma epistemologia ativa da política em contexto, de forma crítica e efêmera.

\section{Metodologia}

Trata-se de um estudo de perfil qualitativo, do tipo exploratório descritivo. As técnicas de pesquisa empregadas foram a entrevista semiestruturada e a observação participante.

O estudo exploratório-descritivo permite a construção e organização de dados com clareza de informações referentes a uma determinada população, possibilitando os usos dos mesmos, para análise por outros pesquisadores com abordagens diferentes (MARCONI e LAKATOS, 2010).

Durante a pesquisa de campo, foram aplicadas entrevistas do tipo semiestruturada e elaborados relatórios que continham as observações da pesquisadora durante todo o desenvolvimento do estudo. Entrevistas do tipo semiestruturada permitem ao pesquisador formular previamente questões sobre a temática (roteiro), e ao entrevistado a liberdade de propor 
desdobramentos a partir do tema principal (GERHARDT et al., 2009). Foram elaborados dois roteiros de entrevistas, cada um com seis questões, cada qual destinado aos dois tipos de participantes: os intérpretes-criadores e os coreógrafos.

Devido à atuação da pesquisadora como bailarina do Projeto NEPARC, durante todo o processo de composição das obras coreográficas estudadas, fez-se a opção pela técnica metodológica de observação participante para a pesquisa. Esta técnica permite/ autoriza ao observador um contato mais próximo com o objeto de estudo, portanto a utilização dos sentidos como um dos recursos de interpretação. A principal característica da observação participante é "o contato direto do observador com o fenômeno observado, [obtendo] (...) informações sobre a realidade dos atores sociais em seus próprios contextos" (GERHARDT et al., 2009, p. 75).

Para a definição das obras a serem estudadas, foram selecionadas duas coreografias do Projeto. Nortearam esta seleção os seguintes preceitos: 1) trabalhos coreográficos que compunham o espetáculo "Por enquanto é isso...", do NEPARC, no ano de 2013; 2) obras criadas para atuar em espaços públicos (rua); 3) coreógrafos que autorizassem a exposição das obras, através de uma pesquisa. Desta forma, foram selecionadas duas obras, são elas: "Outro Lugar" e "Plástico Bolha".

Em relação aos participantes, foram entrevistados dois coreógrafos referentes aos trabalhos descritos acima, sendo eles: Alex Neoral, da Focus Cia de Dança (RJ), e Vanilto Alves de Freitas (Lakka), do Mono-Blocos (MG).

Quanto aos intérpretes-criadores, colaboraram com a pesquisa bailarinos do Projeto que participaram do processo de composição, manutenção e apresentação das duas obras artísticas selecionadas. Desta forma, três bailarinos atenderam aos critérios definidos nesta pesquisa, sendo um homem e duas mulheres, todos estudantes do Curso de Dança da Universidade Federal de Viçosa (MG).

Por se tratar de um estudo transversal, as entrevistas ocorreram conforme a disponibilidade de cada indivíduo. Devido a isso, a coleta de dados concretizou-se em momentos e espaços diferentes, em conformidade com o tempo de pesquisa delimitado (março de 2014 a fevereiro de 2015) pelo órgão financiador ${ }^{4}$.

Com relação aos aspectos éticos da pesquisa, todos os sujeitos envolvidos no estudo assinaram o Termo de Consentimento Livre e Esclarecido, e o termo de autorização para revelação da identidade dos coreógrafos. A pesquisadora entende que a identificação dos indivíduos auxiliará no entendimento acerca da caracterização das amostras/ coreografias, sendo mantida em sigilo a identidade dos bailarinos.

Os instrumentos que fizeram parte da pesquisa foram: entrevistas

4 Programa Institucional de Bolsas de Iniciação Cientifica, Convênio PROBIC/FAPEMIG/UFV 2014-2015. 
semiestruturadas, relatório que foi sendo construído durante todo o período da pesquisa e um gravador de áudio para registro da entrevista.

Dentro da pesquisa, o relatório desempenhou a funcionalidade de um diário de campo. Nele, foram feitos os registros das observações, descrição de fatos, fenômenos sociais, experiências pessoais do investigador e comentários. $\mathrm{O}$ instrumento teve similitude ao formato de diário de campo dos autores Gerhardt et al. (2009), inspirados nos autores Bogdan e Biklen (1994 apud GERHARDT et al., 2009), que estruturam o diário a partir de uma perspectiva descritiva e reflexiva.

As entrevistas foram gravadas em áudio e transcritas, procedimento que é feito para facilitar consulta e análise. Como estratégia analítica, foi realizada a ordenação dos dados em categorias da seguinte forma: inicialmente, em duas categorias relativas aos participantes, intérpretes-criadores e coreógrafos, que num segundo momento foram subdivididas em subcategorias, obedecendo às temáticas que foram formuladas em momento posterior à entrevista. A pesquisa baseou-se no modelo de análise de conteúdo categorial do autor Bardin (2009), que entende a análise de conteúdo como "um conjunto de técnicas de comunicação". Além disso, foi realizado um cruzamento de informações, respeitando as categorias da pesquisa.

- Processo de construção artística;

- A interferência do espaço na performance;

- A relação da escritura coreográfica e o território urbano;

- Interferências externas, acasos e sugestões do espaço;

- Espaço Urbano e Obra artística: a construção de um diálogo;

\section{Discussão dos resultados}

Percepções e reflexões dos coreógrafos

Analisando as entrevistas percebeuse que todos os artistas entendem a cidade como um campo de atuação, do ambiente/ contexto alvo de discussões sociais, políticas, filosóficas, artísticas e arquitetônicas. A dança como intervenção urbana pode possibilitar esse diálogo, como um discurso, por meio do gesto, sendo construído de forma efêmera em coparticipação com os intérpretes, local e obra artística. Fazer com que a cidade venha a "encontrar-se e renovar-se numa nova política do chão, numa coreopolítica nova em que se possa agir algo mais do que o espetáculo fútil de uma frenética e eterna agitação urbana, [...]" (LEPECKI, 2011, p. 49).

Na entrevista, Lakka se diz utilizar do local/ contexto, em que a obra se dá, como parte constituinte da mesma, sendo essa ação uma das características da arte contemporânea. A dança pensada e concretizada para e em espaços urbanos, públicos, transforma o que, há algumas 
décadas, poderia ser considerado cenário, fantasia e maquete, em uma estrutura complexa, imprevisível e efetiva na obra. "A diversidade de usos do espaço cênico na contemporaneidade, particularmente as experiências cênicas de invasão de espaços públicos, exige uma nova compreensão do funcionamento do próprio espetáculo teatral e a articulação de novos referenciais teóricos" (CARREIRA, 2008, p. 75).

A corpografia, momento dialógico "corpocidade", possui íntima relação com as características "lugar", portanto, como seus códigos sociais de controle que atuarão na composição artística no momento da intervenção. Lakka considera haver dois tipos de códigos sociais, os explícitos, mais tangíveis, e os implícitos, e a este último, intitula de "configuração social do local", ambos são determinantes na efetivação da obra coreográfica, pois definem as características, negociações, portanto a estética da mesma bem como o comportamento do transeunte.

Um exemplo disso é quando comparamos o espaço especializado (teatro) com os espaços públicos (cidade, rua, etc.). No teatro existem diferentes códigos/ normas que são atendidas pelos que dele usufruem profissionalmente, até mesmo sem que sejam enunciadas previamente, como por exemplo: desligar o celular, não conversar no momento do espetáculo, ficar a todo o momento sentado, não intervir na obra, a não ser que seja orientado. Já no território urbano, apesar das características de cada ambiente, não há definição de um padrão de comportamento a ser seguido, cada qual tem liberdade de se expressar sobre o trabalho, podendo agir como um mero espectador, recusar/ negar a intervenção/ proposta e/ ou interagir com a obra artística, tornando-se coautor da mesma.

Assim como a configuração social/ cultural, o tempo e o espaço são fatores determinantes quando se reflete sobre a intervenção urbana. Por exemplo, interferências artísticas urbanas sem aviso prévio, que não façam parte de uma programação, provocam um contexto/ circunstância diferente de quando compõem um cronograma de festival. Quando uma intervenção espetáculo é parte de um programa, o público e local de exposição são preparados (literalmente) para receber tal evento, afetando, neste caso minimizando, de certa forma, o impacto de recebimento/ estranhamento daquela ação.

Ainda sobre a relação corpo-cidade no momento da intervenção, deve-se atentar para a estrutura da obra artística em espaços públicos, pois, certamente, este contexto poderá e/ou sugerirá reconfigurações da escrita coreográfica. Nesse sentido, Alex Neoral reconhece e se utiliza em seu trabalho de momentos de improvisações estruturadas. Uma estratégia criada para e na interação do bailarino com o espaço (rua) e/ou público. Pois, compreende-se neste estudo que toda a estrutura de movimento, bem como a preparação do bailarino, tem de ser pensada a partir das características do 
local, já que, diferentemente de espaços especializados, o do "acaso", a intervenção do espaço e público na obra passam a ser ações inevitáveis. No momento em que a obra é desenvolvida no perímetro urbano, o coreógrafo se permite jogar com perspectivas inéditas, aquelas que surgem do acaso, do inesperado, do que não foi pré-estabelecido, que vem do outro, de fora. Provocando, de certa forma, processos de coautoria, ou seja, quando e onde todos os presentes podem vir a compor aquele trabalho, contexto, circunstância.

Esse tipo de prática acontece desde os anos 60/70, trata-se do que Lehmann (2007, p. 204) denomina de espaço partilhado, para o autor "[...] esses trabalhos desenvolvem uma ampla interação com o público, criando situações que não há diferença entre palco e platéia (sic). [...] o público pode ir e vir como achar conveniente".

Já Carreira (2008) destaca a perspectiva política da relação corpo, cidade e arte, visto que considera "[...] que este atorinvasor, antes de levar para a rua uma profunda e sólida construção, deverá portar uma estrutura flexível cujo eixo estará preparado para a tarefa da invasão" (CARREIRA, 2008, p. 73).

Lakka, nesse sentido, adota em seu trabalho uma escrita baseada em jogos, estratégia que permite a todos os presentes (público, bailarino e espaço) ter e/ou desenvolver um papel dentro da obra artística. Ou seja, a composição é realizada em tempo real sendo regida por "regras/códigos" previamente estabelecidos.

O partilhar o espaço, conforme Lehmann (2007), a perspectiva política da relação corpo cidade e arte, de Carreira (2008), explicitam e confirmam a ideia de jogo implícita neste tipo de intervenção artística. Jogo no qual, segundo Lakka, todos são jogadores, sem hierarquias, onde cada qual conta com as próprias experiências vividas, onde há regras, as que fundam o jogo, aquelas que provocarão a vida/ surgimento da obra. Mas, segundo o coreógrafo, tudo é o vir a ser, regras sempre podem ser modificadas ao longo da intervenção, a estrutura de jogo exige atenção e observação de todos os participantes, pois a cada nova jogada modificam-se códigos, portanto, reconfigura-se toda a composição. Esse tipo de proposta permite a reinvenção da intervenção, ou seja, que uma nova obra seja criada a cada exposição/ ação, pois cada local e jogador são únicos no tempo e momento de sua efetivação.

Trabalhos criados para serem expostos em locais alternativos e/ou na cidade têm características peculiares, uma delas, segundo Alex, é: por mais que sejam aplicadas preparações corporais para os bailarinos, como ensaio/ testes em estúdios, quanto expostos em espaços públicos, é o "aprender-fazendo" que prepara o intérprete para atuar na cidade. Segundo o coreógrafo, a experiência é o melhor mecanismo de preparação do bailarino, estar em contato direito com o chão irregular, o barulho do trânsito, 
o cachorro latindo, proporciona ao intérprete a tomada de decisão (uma jogada) que fará parte da composição da obra. Cada posicionamento tomado, ora pelo bailarino, ora pelo transeunte ou espaço, trata-se de uma reposta artística, política e social que configura e articula o discurso do gesto.

Este contexto acaba por estabelecer uma relação social triangular entre bailarinopúblico-espaço, que a todo o momento de interferência, não importando de quem, produz um constante diálogo, no qual cada um possui autonomia para rejeitar, assimilar ou até mesmo intervir nas relações surgidas. Esta vulnerabilidade poderosa leva a todos a lidar com o imprevisto, aguçar os sentidos, perspectiva que permite aos participantes compreender, como Cohen, que "A performance é basicamente uma arte de intervenção, modificadora, que visa causar uma transformação" (COHEN, 1989, p. 45-46).

Alex relata duas experiências de intervenção em espaços alternativos, primeiramente, na rua, quando um bêbado tentou integrar-se ao grupo, e, na ocasião, o coreógrafo decidiu ignorar a presença do homem; num segundo momento, também numa intervenção em espaço público, um cachorro insinua morder os bailarinos. Alex comentou que começou a contracenar com o animal, numa tentativa de retirá-lo do espaço, contudo, o cão fugia e voltava a todo o instante, o cachorro tornando-se parte do trabalho, mesmo que o propósito do coreógrafo não fosse este.

1. Quadro comparativo entre perspectivas dos dois coreógrafos sobre espaços de apresentações especializados e públicos/ urbanos.

\begin{tabular}{|c|c|c|}
\hline \multirow{8}{*}{$\begin{array}{l}\text { Alex } \\
\text { Neoral }\end{array}$} & $\begin{array}{c}\text { Rua (espaços } \\
\text { públicos/ urbanos) }\end{array}$ & $\begin{array}{l}\text { Teatro (espaços } \\
\text { especializados) }\end{array}$ \\
\hline & $\begin{array}{l}\text { Menor concentração } \\
\text { do bailarino e do } \\
\text { público }\end{array}$ & $\begin{array}{l}\text { Maior concentração do } \\
\text { bailarino e do público }\end{array}$ \\
\hline & $\begin{array}{l}\text { Maior aproximação } \\
\text { com o público }\end{array}$ & $\begin{array}{l}\text { Menor aproximação } \\
\text { com o público }\end{array}$ \\
\hline & $\begin{array}{l}\text { Maiores limitações } \\
\text { técnicas, espaciais, } \\
\text { estruturais }\end{array}$ & $\begin{array}{l}\text { Menores limitações } \\
\text { técnicas, espaciais, } \\
\text { estruturais }\end{array}$ \\
\hline & $\begin{array}{l}\text { Liberdade de tempo e } \\
\text { espaço da apresen- } \\
\text { tação }\end{array}$ & $\begin{array}{l}\text { Delimitação de tempo } \\
\text { e espaço da apresen- } \\
\text { tação }\end{array}$ \\
\hline & $\begin{array}{l}\text { Maior interferência do } \\
\text { espaço na obra }\end{array}$ & $\begin{array}{l}\text { Menor interferência do } \\
\text { espaço na obra }\end{array}$ \\
\hline & $\begin{array}{l}\text { Dificuldade para criar } \\
\text { ambientação (cenário, } \\
\text { acústica do espaço, } \\
\text { luz, etc.) }\end{array}$ & $\begin{array}{l}\text { Facilidade para criar } \\
\text { ambientação (cenário, } \\
\text { acústica do espaço, } \\
\text { luz, etc.) }\end{array}$ \\
\hline & $\begin{array}{l}\text { Público variado (hete- } \\
\text { rogêneo) }\end{array}$ & Público seleto \\
\hline \multirow{3}{*}{ Lakka } & $\begin{array}{l}\text { Comportamento } \\
\text { social indefinido }\end{array}$ & $\begin{array}{l}\text { Comportamento social } \\
\text { definido }\end{array}$ \\
\hline & $\begin{array}{l}\text { Possui maior quanti- } \\
\text { dade de variáveis }\end{array}$ & $\begin{array}{l}\text { Possui menor quanti- } \\
\text { dade de variáveis }\end{array}$ \\
\hline & $\begin{array}{l}\text { Público variado (hete- } \\
\text { rogêneo) }\end{array}$ & Público seleto \\
\hline
\end{tabular}

Percepções e reflexões dos intérpretescriadores

Segundo os bailarinos, nos momentos dialógicos com os coreógrafos, foram abordadas questões sobre as movimentações, estrutura coreográfica e corporeidade dos bailarinos. Para os intérpretes, intervir em tais localidades exige estudo e discussão prévia, para que possam "ajustar" seus corpos ao espaço e vice-versa. A dança contemporânea 
é uma forma de arte em construção e transformação continuada, "[...] utiliza de diferentes técnicas corporais, modos de apresentação, pluralidades estéticas, ambiguidades (sic), descontinuidade, heterogeneidade, diversidade de códigos, subversão e multilocalização" (SÃO JOSÉ, 2011, p. 4-5).

O bailarino 1, ao fazer menção ao espaço em que foi realizada a montagem/ manutenção dos trabalhos, disse que todo o processo foi feito no prédio do Curso de Dança da UFV, em salas especializadas, com pisos especiais com amortecimento, espelhos, barras, entre outras tecnologias. E destaca, a seu modo, certa preocupação com a discrepância entre o espaço de treinamento e o local de exposição. Consideração que reafirma o entendimento de Carreira, mesmo que ainda em micro escala, sem que tenha sido um projeto pretensamente politizado:

A rua é o espaço inóspito que se opõe ao conforto e à segurança dos espaços íntimos. [...] Nesta situação o espetáculo se aproximaria das condições que se assemelham aos momentos fundacionais do teatro antes que esta linguagem fosse encerrada nos espaços enclausurados e altamente estratificados das salas teatrais. (2008, p. 74)

Sobre a interferência do espaço na performance, o bailarino 2 destaca a importância da flexibilidade exigida na ação do bailarino e na obra artística, uma vez que será e é imprescindível se adequar ao local, aos acasos sugeridos pelo contexto, tais como bêbados intervindo no espetáculo, animais e características do local (chão, comércio, fluxo de pessoas, etc.), conforme relatou Alex.

Ainda sobre a interferência do espaço na obra, o bailarino 1 destacou ter percebido que, nas primeiras apresentações do NEPARC, o grupo aparentava estar desconfortável com as intervenções sugeridas pelo ambiente. Ele disse que foi preciso tempo para que os participantes compreendessem e/ou de fato jogassem com as características do local para e /na construção do trabalho. As representações dos dois intérpretes sobre a relação espaço/ contexto, corpo e criação, evidenciam a consciência da reciprocidade de interferências, ou seja, o reconhecimento de que o espaço urbano interfere na obra, na atuação dos bailarinos e vice-versa.

Conforme o bailarino 2, o trabalho de preparação realizado por Lakka promoveu um bom resultado, uma vez que, o treinamento dado pelo coreógrafo ajudou o grupo a fazer a manutenção da obra. Houve consenso quanto à importância de promover ensaios na rua, mencionando a falta dos mesmos, durante a criação/ manutenção dos trabalhos.

O bailarino 3 complementa seu discurso dizendo que a composição/ manutenção de um trabalho em estúdio destinado para rua pode funcionar, desde que a abordagem aproxime-se da realizada, o que, conforme sua percepção, foi alcançado na preparação proposta por Lakka. 
A percepção dos bailarinos sobre a relação entre intérprete-criador e públicos nos diferentes espaços (rua e teatro) foi temática do roteiro, e todos os artistas concordaram ao dizer que esta relação é divergente. O intérprete 3 enfatiza o distanciamento sugerido pelo espaço físico do teatro: sua percepção é que o local privilegia aspectos estéticos da coreografia e promove um empobrecimento sensorial bailarinopúblico, em oposição à rua, que suscita a aproximação. Ele exemplifica, relatando o esforço exercido pelo dançarino, que é visualizado pela plateia quando o trabalho é realizado no decoro urbano.

Assim posto, pode-se observar a importância destacada pelos bailarinos no que se refere à preparação da corporeidade, e a importância de pensar a obra que é destinada a rua desde sua criação. É necessário refletir sobre o local de manutenção da obra, já que todos os bailarinos consideram que a falta de realização de ensaios no espaço urbano pode comprometer o trabalho e até mesmo colocar em risco a integridade do intérprete.
2. Quadro de representações dos bailarinos sobre os espaços especializados e público/ urbanos.

\begin{tabular}{|c|c|c|}
\hline \multirow{4}{*}{ Bailarino 1} & $\begin{array}{l}\text { Rua (espaço } \\
\text { urbano) }\end{array}$ & $\begin{array}{l}\text { Teatro (espaço } \\
\text { especializado) }\end{array}$ \\
\hline & $\begin{array}{l}\text { Não há um controle } \\
\text { da quantidade do } \\
\text { público }\end{array}$ & $\begin{array}{l}\text { Controle da quanti- } \\
\text { dade do público }\end{array}$ \\
\hline & $\begin{array}{l}\text { Proporciona um } \\
\text { número maior de } \\
\text { experiências para o } \\
\text { bailarino }\end{array}$ & $\begin{array}{l}\text { Proporciona um } \\
\text { número menor de } \\
\text { experiências para o } \\
\text { bailarino }\end{array}$ \\
\hline & $\begin{array}{l}\text { Necessita de um } \\
\text { estado de presença } \\
\text { maior do bailarino, } \\
\text { devido às adapta- } \\
\text { ções constantes }\end{array}$ & $\begin{array}{l}\text { Não ocorrem tantas } \\
\text { adaptações }\end{array}$ \\
\hline \multirow{6}{*}{ Bailarino 2} & $\begin{array}{l}\text { Maior interferência } \\
\text { do espaço na obra }\end{array}$ & $\begin{array}{l}\text { Menor interferência } \\
\text { do espaço na obra }\end{array}$ \\
\hline & $\begin{array}{l}\text { Público variado } \\
\text { (heterogêneo) }\end{array}$ & Público seleto \\
\hline & $\begin{array}{l}\text { Espaço adaptado } \\
\text { para apresentações } \\
\text { artísticas }\end{array}$ & $\begin{array}{l}\text { Espaço próprio } \\
\text { para apresentações } \\
\text { artísticas }\end{array}$ \\
\hline & $\begin{array}{l}\text { Suscita maior ten- } \\
\text { são no bailarino }\end{array}$ & $\begin{array}{l}\text { Suscita menor ten- } \\
\text { são no bailarino }\end{array}$ \\
\hline & $\begin{array}{l}\text { Favorece a concen- } \\
\text { tração de pessoas } \\
\text { de diferentes áreas } \\
\text { de atuação }\end{array}$ & $\begin{array}{l}\text { Favorece a concen- } \\
\text { tração de pessoas } \\
\text { com maior vivência } \\
\text { e senso crítico de } \\
\text { arte }\end{array}$ \\
\hline & $\begin{array}{l}\text { Maior interação } \\
\text { bailarino-público }\end{array}$ & $\begin{array}{l}\text { Menor interação } \\
\text { bailarino-público }\end{array}$ \\
\hline \multirow{4}{*}{ Bailarino 3} & $\begin{array}{l}\text { Maior interação } \\
\text { bailarino-público }\end{array}$ & $\begin{array}{l}\text { Menor interação } \\
\text { bailarino-público }\end{array}$ \\
\hline & $\begin{array}{l}\text { Lugar de divulgação } \\
\text { de espetáculos }\end{array}$ & \\
\hline & $\begin{array}{l}\text { Maiores limitações } \\
\text { técnicas, espaciais, } \\
\text { estruturais }\end{array}$ & $\begin{array}{l}\text { Menores limitações } \\
\text { técnicas, espaciais, } \\
\text { estruturais }\end{array}$ \\
\hline & $\begin{array}{l}\text { Sofre interferên- } \\
\text { cias climáticas e } \\
\text { externas }\end{array}$ & $\begin{array}{l}\text { Não sofre interferên- } \\
\text { cias climáticas nem } \\
\text { externas }\end{array}$ \\
\hline
\end{tabular}

\section{Considerações Finais}

Com base nos resultados/ discussões realizadas, pode-se observar que as intervenções artísticas que buscam, no 
território público urbano, um ambiente para apresentação e exposição de obras coreográficas, possuem na cidade a potencialidade de construção dialógica no âmbito político, social, filosófico e arquitetônico.

A dança, arte efêmera essencialmente política, atua como meio de promoção dessa relação corpo-cidade, explora as possibilidades propostas pelas configurações urbanas. A cidade como local de diálogo, expressão e experimentações, pois sua ação questiona os códigos predefinidos, construindo e reconstruindo os ambientes.

Observou-se que os códigos físicos e implícitos da rua devem ter uma atenção quando for propor algum tipo de intervenção para tal espaço, pois essas caraterísticas são fatores determinantes quando algo for intervir no cotidiano do local que foi previamente estabelecido.

A partir disso, entende-se que uma obra que tem como o território urbano um espaço de veiculação, este fato deve permear todo o processo artístico, onde o coreógrafo deve-se atentar para as situações de acaso que o local irá promover, atuando de forma concreta na escrita coreográfica.

Desta forma, a preparação artística pode ser realizada de diferentes formas, contudo, é bom que o coreógrafo utilize formas de preparação que se aproximem da realidade que será vivenciada, para que os intérpretes possam desconstruir a estrutura coreográfica de forma mais orgânica, sempre incluindo na composição as informações advindas do local.

Nesse estudo, conseguiu-se observar duas alternativas encontradas pelos coreógrafos como meio de preparação e discussão dos bailarinos, o "aprenderfazendo", aplicado pelo Alex, e a estrutura baseada em jogos proposta por Lakka.

Percebe-se desta forma que trabalhos destinados à rua necessitam de uma preparação física especializada, desde a criação da obra até a apresentação do espetáculo, e se deve procurar locais de treinamento que se aproximem do realizado no trabalho, para que não se comprometam nem a obra nem os bailarinos.

No que concerne à relação social triangular bailarino-público-espaço, os dois artistas-coreógrafos concordaram ao dizer que a definição do local de atuação irá influenciar de forma direta essa relação. Ambos comentaram sobre o comportamento da plateia nos espaços especializados em comparação aos espaços públicos.

Em conclusão, a cidade é entendida como um lugar de atuação artística, sendo que há especificidades para atuar em tal espaço. É necessário refletir sobre uma preparação artística que leve em consideração as características do espaço e desenvolva nos bailarinos autonomia para que os mesmos atuem como coautor da obra e consigam responder às propostas realizadas pelo local. 
Recebido em: 30/11/2016

Aceito em: 24/02/2017

\section{Referências Bibliográficas}

BARDIN, L. Análise de Conteúdo. Lisboa: Edições 70; LDA, 2009.

BRITTO, F. D.; JACQUES, P. B. Cenografias e Corpografias Urbanas: um diálogo sobre as relações corpo e cidade. Cadernos PPG-AU/UFBA, Salvador, Vol. 7, edição especial, 2008a.

BRITTO, F. D.; JACQUES, P. Corpografias urbanas: relações entre o corpo e a cidade. In: LIMA, E. F. W. (org.). Espaço e Teatro: do edifício teatral à cidade como palco. Rio de Janeiro: 7 letras, 2008b.

BRITTO, F. D.; JACQUES, P. Corpocidade: Arte enquanto micro-resistência urbana. Fractal: Revista de Psicologia, Niterói, v. 21, n. 2, maio/ago. 2009.

CARREIRA, A. Teatro de invasão: redefinido a ordem da cidade. In: LIMA, E. F. W. (org.). Espaço e Teatro: do edifício teatral à cidade como palco. Rio de Janeiro: 7 letras, 2008.

CERTEAU, M. A Invenção do cotidiano: Artes de fazer. Petrópolis: Vozes, 1994.

COHEN, R. Performance como Linguagem: criação de um espaçotempo de experimentação. São Paulo: Perspectiva; USP, 1989.

DEBORD, G. A sociedade do espetáculo.
Rio de Janeiro: Contraponto, 1997.

FAZENDA, M. J. Dança Teatral: Ideias, Experiências, Acções. Lisboa: Celta Editora, 2007.

FREITAS, V. A. Sugestões para uma Cidade Habitar um Corpo. In: VI Congresso Brasileiro de Pesquisa e Pósgraduação em Artes Cênicas, 2010, São Paulo. Anais do VI Congresso Brasileiro de Pesquisa e Pós-graduação em Artes Cênicas. Uberlândia: Associação Brasileira de Pesquisa e Pós-graduação em Artes Cênicas, 2010.

FREITAS, V. Para uma cidade habitar um corpo: proposições de uso do espaço urbano e seus acréscimos na formação do artista cênico. 2011. 117 f. Dissertação (Mestrado em Artes) - Instituto de Artes, Universidade Federal de Uberlândia, Uberlândia. 2011.

GERHARDT, T. E. et al. Estrutura do Projeto de Pesquisa. In: GERHARDT, T. E.; SILVEIRA, D. T. Métodos de pesquisa. Porto Alegre: Editora da UFRGS, 2009.

LEHMANN, Hans-Thies. O teatro pósdramático. São Paulo: Cosac Naify, 2007.

LEPECKI, André. Coreopolítica e coreopolícia. Ilha - Revista de Antropologia. Florianópolis, v. 13, n. 1, p.41-60, jan/jun. 2011.

MARCONI, M. A.; LAKATOS, E. M. Fundamentos de metodologia científica. 7. ed. São Paulo: Atlas, 2010.

NEPARC. Núcleo de Estudos e 
Práticas Artístico-Corporais. Programa Argumentos do Corpo. Disponível em: $<$ http://www.argumentosdocorpo.com.br/ neparc.html>. Acesso em 15 jun. 2015.

SÃo José, A. M. de. Dança Contemporânea: Um conceito possível? In: V Colóquio Internacional "Educação e Contemporaneidade", 2011, São Cristóvão. Anais do V Colóquio Internacional "Educação e Contemporaneidade". São Cristóvão: Universidade Federal de Sergipe, 2011.

SENNET, R. Carne e Pedra: O Corpo é a Cidade na Civilização Ocidental. $2^{\circ}$ Ed. Rio de Janeiro: Record, 2001. 